\title{
The role of hybrid FDG-PET/MRI on decision-making in presurgical evaluation of drug-resistant epilepsy
}

Márton Tóth ${ }^{1^{*}} \mathbb{D}$, Péter Barsi ${ }^{2}$, Zoltán Tóth ${ }^{3,4}$, Katalin Borbély ${ }^{5}$, János Lückl ${ }^{3}$, Miklós Emri ${ }^{4,6}$, Imre Repa $^{3}$, József Janszky ${ }^{1,7}$, Tamás Dóczi ${ }^{7,8}$, Zsolt Horváth ${ }^{8}$, Péter Halász ${ }^{9}$, Vera Juhos ${ }^{10}$, Csilla Gyimesi ${ }^{1}$, Beáta Bóné ${ }^{1}$, Diána Kuperczkó ${ }^{1}$, Réka Horváth ${ }^{1}$, Ferenc Nagy ${ }^{11}$, Anna Kelemen", Zsófia Jordán ${ }^{9}$, Ákos Újvári ${ }^{9}$, Koichi Hagiwara ${ }^{12}$, Jean Isnard ${ }^{13}$, Endre Pál ${ }^{1}$, Attila Fekésházy ${ }^{3,4}$, Dániel Fabó ${ }^{9 \dagger}$ (D) and Zsolt Vajda ${ }^{3,8+}$

\begin{abstract}
Background: When MRI fails to detect a potentially epileptogenic lesion, the chance of a favorable outcome after epilepsy surgery becomes significantly lower (from 60 to $90 \%$ to 20-65\%). Hybrid FDG-PET/MRI may provide additional information for identifying the epileptogenic zone. We aimed to investigate the possible effect of the introduction of hybrid FDG-PET/MRI into the algorithm of the decision-making in both lesional and non-lesional drug-resistant epileptic patients.
\end{abstract}

Methods: In a prospective study of patients suffering from drug-resistant focal epilepsy, 30 nonlesional and 30 lesional cases with discordant presurgical results were evaluated using hybrid FDG-PET/MRI.

Results: The hybrid imaging revealed morphological lesion in 18 patients and glucose hypometabolism in 29 patients within the nonlesional group. In the MRI positive group, 4 patients were found to be nonlesional, and in 9 patients at least one more epileptogenic lesion was discovered, while in another 17 cases the original lesion was confirmed by means of hybrid FDG-PET/MRI. As to the therapeutic decision-making, these results helped to indicate resective surgery instead of intracranial EEG (iEEG) monitoring in 2 cases, to avoid any further invasive diagnostic procedures in 7 patients, and to refer 21 patients for iEEG in the nonlesional group. Hybrid FDG-PET/MRI has also significantly changed the original therapeutic plans in the lesional group. Prior to the hybrid imaging, a resective surgery was considered in 3 patients, and iEEG was planned in 27 patients. However, 3 patients became eligible for resective surgery, 6 patients proved to be inoperable instead of $\mathrm{iEEG}$, and 18 cases remained candidates for iEEG due to the hybrid FDG-PET/MRI. Two patients remained candidates for resective surgery and one patient became not eligible for any further invasive intervention.

Conclusions: The results of hybrid FDG-PET/MRI significantly altered the original plans in 19 of 60 cases. The introduction of hybrid FDG-PET/MRI into the presurgical evaluation process had a potential modifying effect on clinical decision-making.

\footnotetext{
* Correspondence: toth.marton@pte.hu

Marton Toth and Daniel Fabo first and senior author.

${ }^{\dagger}$ Dániel Fabó and Zsolt Vajda contributed equally to this work.

'Department of Neurology, Medical School, University of Pécs, Rét u. 2, Pécs H-7623, Hungary

Full list of author information is available at the end of the article
}

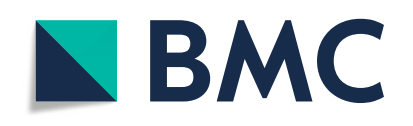

(- The Author(s). 2021 Open Access This article is licensed under a Creative Commons Attribution 4.0 International License, which permits use, sharing, adaptation, distribution and reproduction in any medium or format, as long as you give appropriate credit to the original author(s) and the source, provide a link to the Creative Commons licence, and indicate if changes were made. The images or other third party material in this article are included in the article's Creative Commons licence, unless indicated otherwise in a credit line to the material. If material is not included in the article's Creative Commons licence and your intended use is not permitted by statutory regulation or exceeds the permitted use, you will need to obtain permission directly from the copyright holder. To view a copy of this licence, visit http://creativecommons.org/licenses/by/4.0/. The Creative Commons Public Domain Dedication waiver (http://creativecommons.org/publicdomain/zero/1.0/) applies to the data made available in this article, unless otherwise stated in a credit line to the data. 
Trial registration: Trial registry: Scientific Research Ethics Committee of the Medical Research Council of Hungary. Trial registration number: 008899/2016/OTIG. Date of registration: 08 February 2016.

Keywords: Drug-resistant epilepsy, Hybrid FDG-PET/MRI, Clinical decision-making, Preoperative workflow, Epilepsy surgery

\section{Background}

Epilepsy is one of the most prevalent neurological diseases with an incidence of $0.4-1 \%$ and a prevalence of $0.4-1 \%[1,2]$. Approximately $23-30 \%$ of the patients are drug-resistant [3-6]. In these cases surgical resection constitutes the best therapeutic option towards achieving seizure freedom [7-11]. In $60-70 \%$ of the patients, noninvasive video-EEG monitor and cranial MRI can be conclusive regarding resective surgery without additional investigation(s). In the remaining proportion of the patients, invasive EEG (iEEG) exploration with intracranial electrodes (subdural or depth electrodes) plays a pivotal role in nonlesional drug-resistant epilepsy, or temporal or extratemporal lesional epilepsy with discordant electro-clinical results [12-16]. Epileptologists might have 4 reasonable options for patients with focal onset medically intractable epilepsy: (1) resective surgery without iEEG investigation, (2) iEEG exploration, (3) neuromodulation therapies such as vagus nerve stimulation (VNS) or deep brain stimulation (DBS), (4) giving new antiepileptic drug(s). Among these possibilities, resective surgery can achieve a decidedly higher seizure-freedom rate than the others [9-11]. When MRI fails to detect a potentially epileptogenic lesion, the chances of a favourable outcome after epilepsy surgery become significantly lower (from 60 to $90 \%$ to $20-65 \%$ ) [10, 11]. Also in this workflow, FDG-PET/MRI coregistration can be utilized to guide a second look at MRI studies previously reported as nonlesional, thus underpinning decision-making [17]. Some epilepsy centers reported the role of PET/MRI coregistration was finding lesion(s) in nonlesional drug-resistant epilepsy patients [18-21]. Another option is the hybrid FDG-PET/MRI in preparation for epilepsy surgery in both lesional and nonlesional cases, providing additional sensitivity for detecting possible epileptic foci [22-24].

The aim of the present study was to investigate the possible effect of the results of hybrid FDG-PET/MRI on the decision-making by the epileptologist in both lesional and nonlesional drug-resistant epileptic patients. For this purpose, we selected two drug-resistant epileptic patient groups of the same size (either lesional or nonlesional cases), where the noninvasive video-EEG monitor and brain MRI were not conclusive regarding the resective surgery. We hypothesized that the results of hybrid
FDG-PET/MRI may affect the initial judgement of the presurgical team: (1) the patient is eligible for iEEG exploration; or (2) eligible for resective surgery; or (3) the patient is not eligible for any further invasive procedure. Thus, in the present study, findings related to the alterations of decision-making were analyzed in detail with respect to imagery results (FDG-PET and MRI).

\section{Methods \\ Subjects}

We prospectively selected 60 adult patients (35 males, 25 females, mean age: 33.02, range:18-55 years) undergoing pre-surgical evaluation for drug-resistant, focalonset epilepsy at two tertiary academic medical centers: (1) Department of Neurology, University of Pécs and (2) National Institute of Clinical Neurosciences, Budapest. Of the patients, all suffering from focal-onset epilepsy, 52 were right-handed and 8 were left-handed. Patients with previous history of epilepsy surgery were not included. Patients were divided into groups based on whether they were lesional (30 patients, for details please see Table 2) with discordant investigational results or nonlesional (30 patients, for details please see Table 1).

MRI examinations at this stage of presurgical evaluation were acquired on 3 Tesla scanners (3 T Magnetom TIM Trio, Siemens) and contained the following sequences: i) 2D T2-weighted axial turbospin-echo (TSE) (slice thickness $4.0 \mathrm{~mm}$, TE/TR: $74 / 6450 \mathrm{~ms}, 120^{\circ}$ flip angle, matrix $280 \times 320$ interpolated to $560 \times 640$, voxel size: $0.34 \times 0.34 \times 4 \mathrm{~mm}$, scan duration $0: 52 \mathrm{~s}$ ); ii) $2 \mathrm{D}$ T2weighted coronal TSE (slice thickness $3.0 \mathrm{~mm}$, TE/TR: $93 / 6980 \mathrm{~ms}, 120^{\circ}$ flip angle, matrix $280 \times 320$ interpolated to $560 \times 640$, voxel size: $0.34 \times 0.34 \times 4 \mathrm{~mm}$, scan duration 1:45 min); iii) 2D T2-weighted coronal TSE fluid-attenuated inversion recovery (FLAIR) (slice thickness $3.0 \mathrm{~mm}$, TE/TR: $123 / 9000 \mathrm{~ms}, 120^{\circ}$ flip angle, matrix $192 \times 256$, voxel size: $0.86 \times 0.86 \times 3 \mathrm{~mm}$, scan duration 3:36 min); iv) 3D sagittal isotropic Magnetization Prepared Rapid Acquisition Gradient Echo (MPRAGE) (slice thickness $0.98 \mathrm{~mm}$, TE/TR: 2.53/ $1900 \mathrm{~ms}$, $9^{\circ}$ flip angle, matrix $256 \times 256$, voxel size: $0.98 \times 0.98 \times 0.98 \mathrm{~mm}$, scan duration $8: 50 \mathrm{~min})$; v) $3 \mathrm{D}$ axial susceptibility weighted imaging (SWI) (slice thickness $1.5 \mathrm{~mm}$, TE/TR: $20 / 27 \mathrm{~ms}, 15^{\circ}$ flip angle, matrix $182 \times 256$, voxel size: $0.9 \times 0.9 \times 1.5 \mathrm{~mm}$, scan duration 4 : 


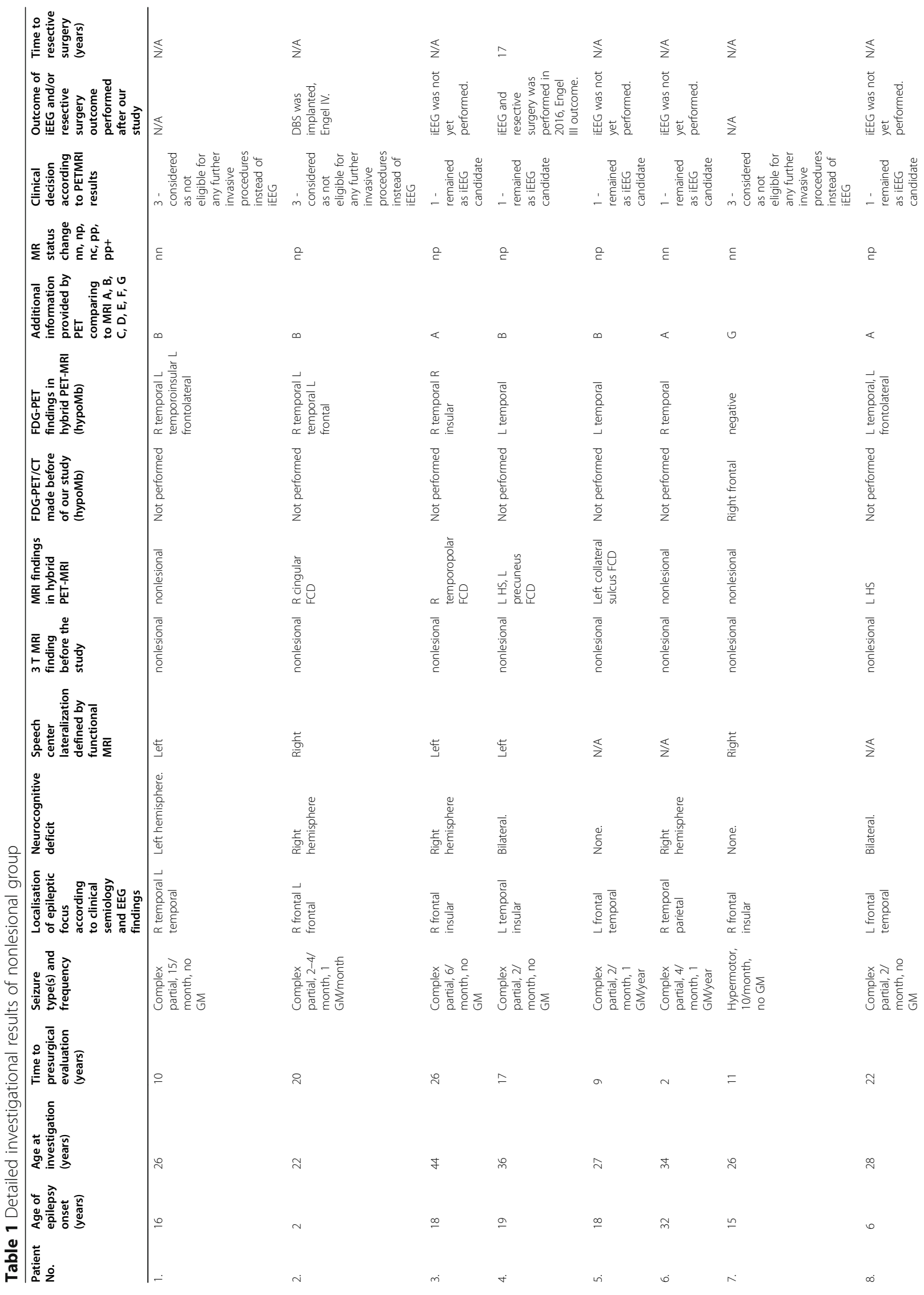




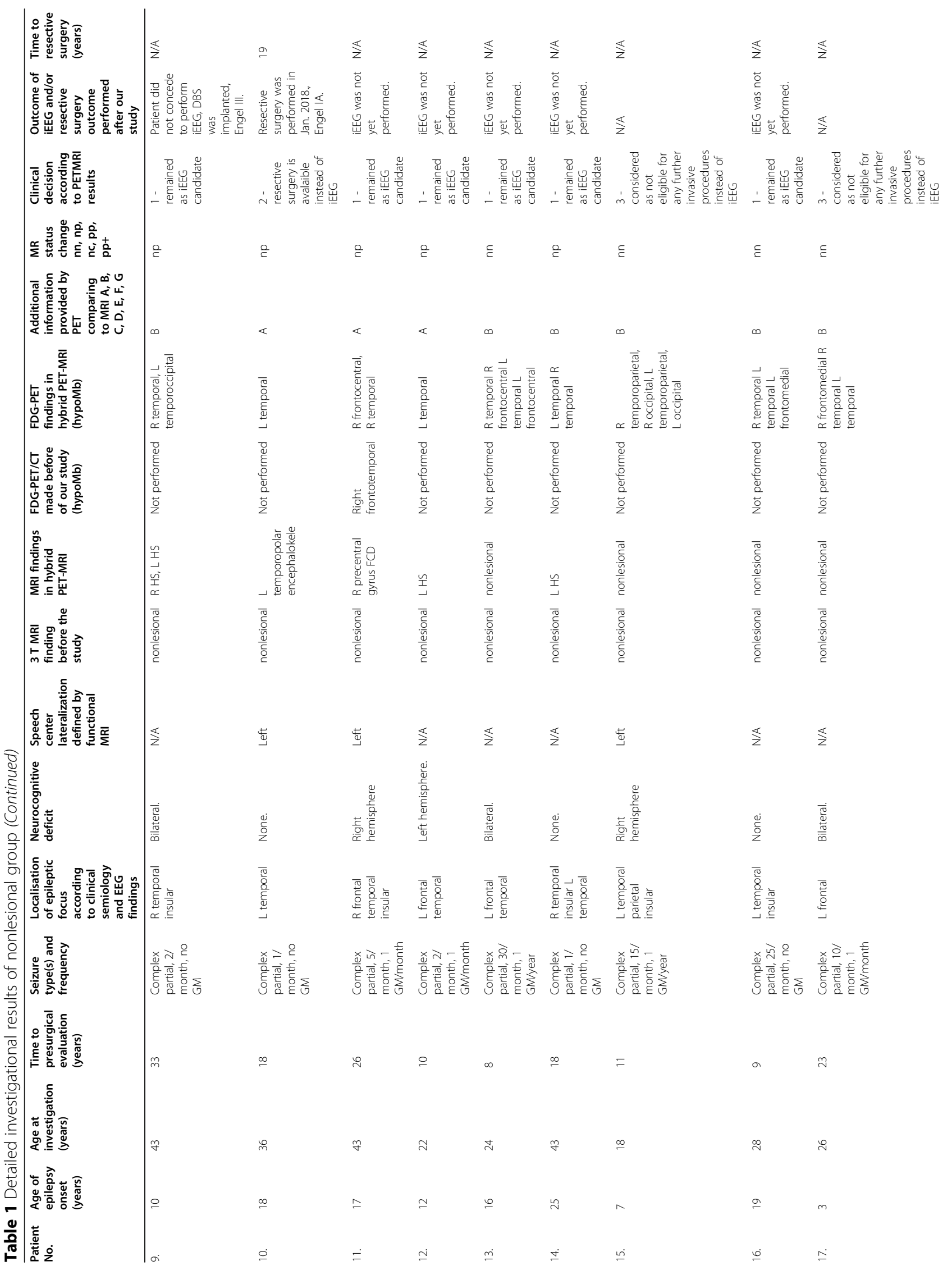




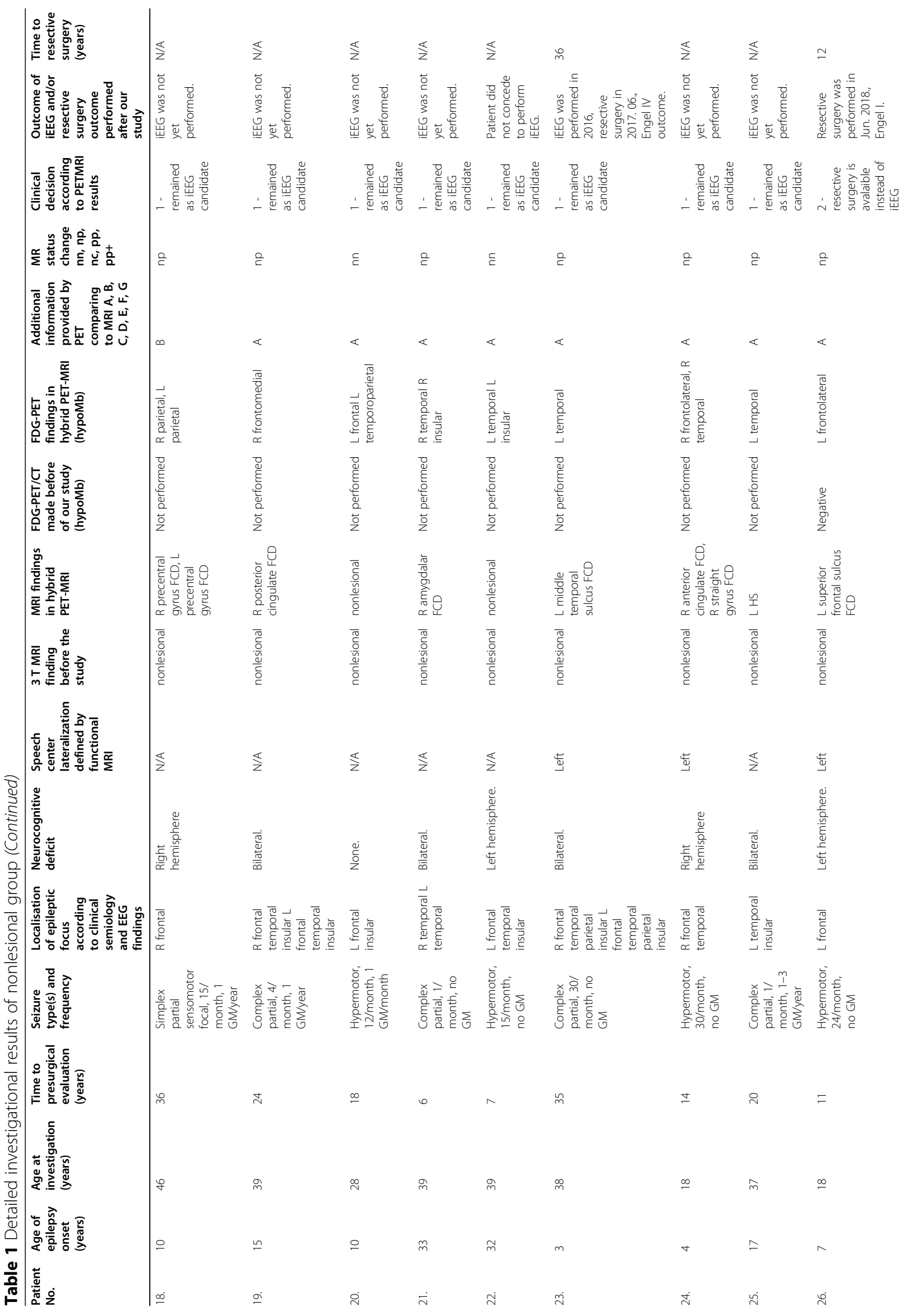




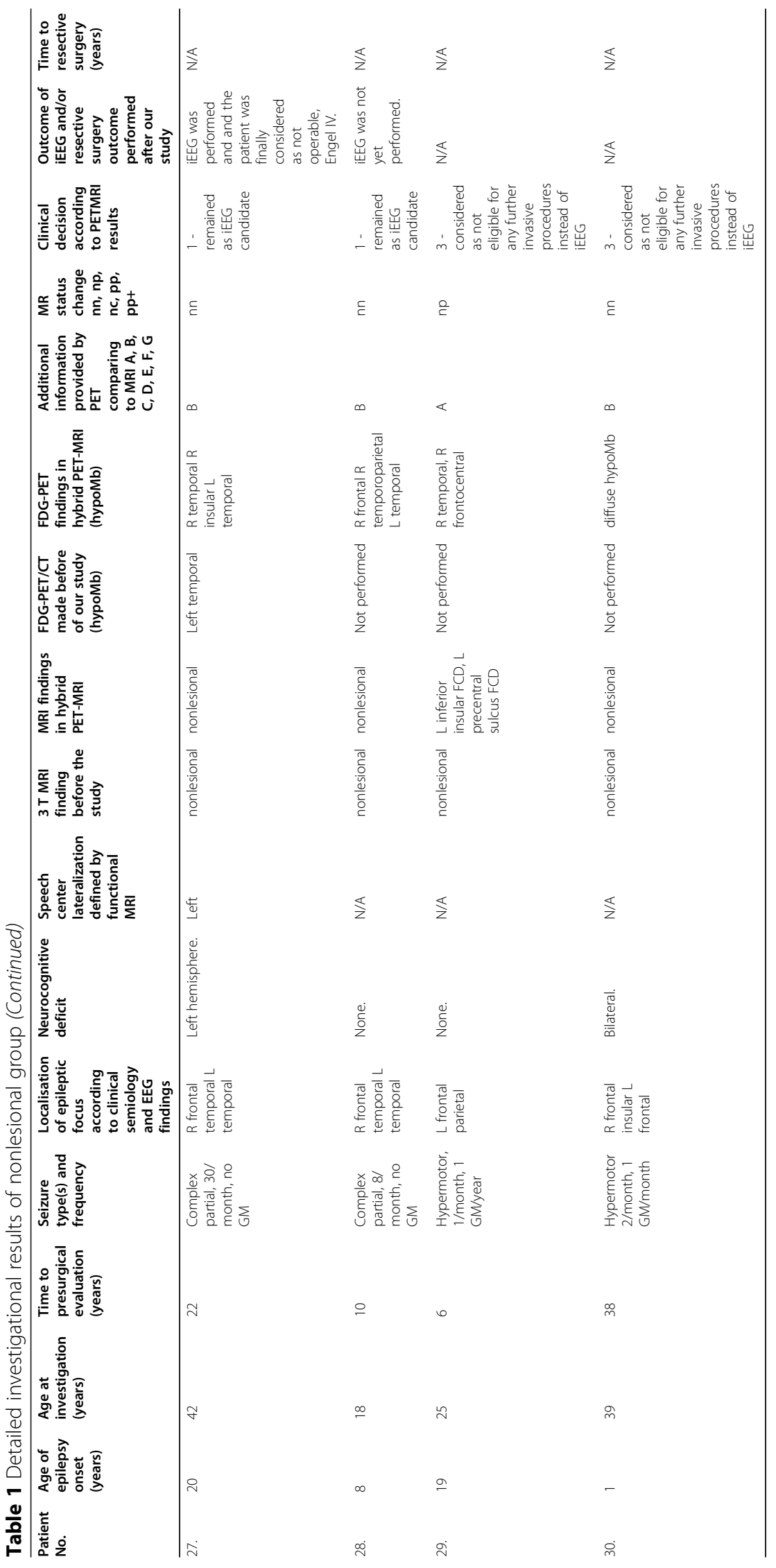


$05 \mathrm{~min})$; vi) 2D axial EPI diffusion-weighted imaging (DWI) (slice thickness $3.0 \mathrm{~mm}$, TE/TR: $91 / 4800 \mathrm{~ms}$, bvalues 0,500 and $1000 \mathrm{~s} / \mathrm{mm} 2$, matrix $168 \times 192$, voxel size: $1.2 \times 1.2 \times 3 \mathrm{~mm}$, scan duration $2: 30 \mathrm{~s}$ ) and vii) $3 \mathrm{D}$ axial time-of-flight (TOF) MRA (slice thickness $0.7 \mathrm{~mm}$, TE/TR: $3.86 / 22 \mathrm{~ms}$, matrix $202 \times 384$, voxel size: $0.58 \times$ $0.58 \times 0.7 \mathrm{~mm}$, scan duration $6: 12 \mathrm{~s}$ ).

All patients signed a written consent approved by Scientific Research Ethics Committee of the Medical Research Council of Hungary (008899/2016/OTIG).

\section{Procedure and material}

All of the patients underwent presurgical examinations: routine epilepsy clinic visits, noninvasive video-EEG monitoring, cranial MRI following the standard epilepsy protocol [25-28] and clinical semiology was evaluated by two presurgical teams. Before FDG-PET/MRI became available, some patients underwent PET/CT when MRI was negative or clinical and EEG findings suggested multiple seizure foci. An algorithm describing the steps of presurgical evaluation at our centers can be seen on Fig. 1. A total of 60 patients underwent pre-surgical evaluations with hybrid FDG-PET/MR from June 2016 until January 2018.

A hybrid FDG-PET/MRI system (Siemens Biograph mMR, Siemens Heathineers, Erlangen, Germany) consisting of $3 \mathrm{~T}$ Verio magnet and MR compatible LSO crystal based APD PET detector system allowing simultaneous PET/MRI acquisition was used. The device was settled in Baka József Diagnostic Center, Kaposi Mór Hospital, Kaposvár, Hungary.

The fluorine-18 fluoro-2-deoxyglucose ([18F] FDG) PET imaging was performed according to the guideline of European Association of Nuclear Medicine Neuroimaging Committee [29]. All patients fasted for at least $6 \mathrm{~h}$ before the scan and blood glucose levels were checked prior to FDG administration. Before the scanning procedure the patients were asked to empty their bladder and were positioned comfortably in a quiet, dark room equipped with a video camera. Then a cannula for intravenous administration was placed. A $2 \mathrm{~h}$-long supervision of the patient and $30 \mathrm{~min}$ of video EEG recording was performed before the administration of FDG (bolus of $200 \mathrm{MBq}$ i.v.). We maintained the video-EEG monitoring for the whole uptake phase of FDG to ensure interictal state. If any seizure activities were recorded during video-EEG monitoring, the FDG-PET/MRI investigation was postponed to the following day. The PET/ MRI scan was started 60 min after the FDG administration. For the prevention of movement artifacts, we informed the patients that they should avoid voluntary movements in the scanner. After the scanning procedure the patients were further supervised for two half-lives of the radioisotope decay (ca. $240 \mathrm{~min}$ ). To ensure complete simultaneous PET coverage, a $20 \mathrm{~min}$ and a 35 min list mode PET acquisition were applied. For PET attenuation correction purposes vendor-provided $\mathrm{T} 2$ ultrashort echo time (UTE) sequence was used, $\mu$ Maps were

\section{Algorithm for presurgical evaluation of drug-resistant epilepsy patients}

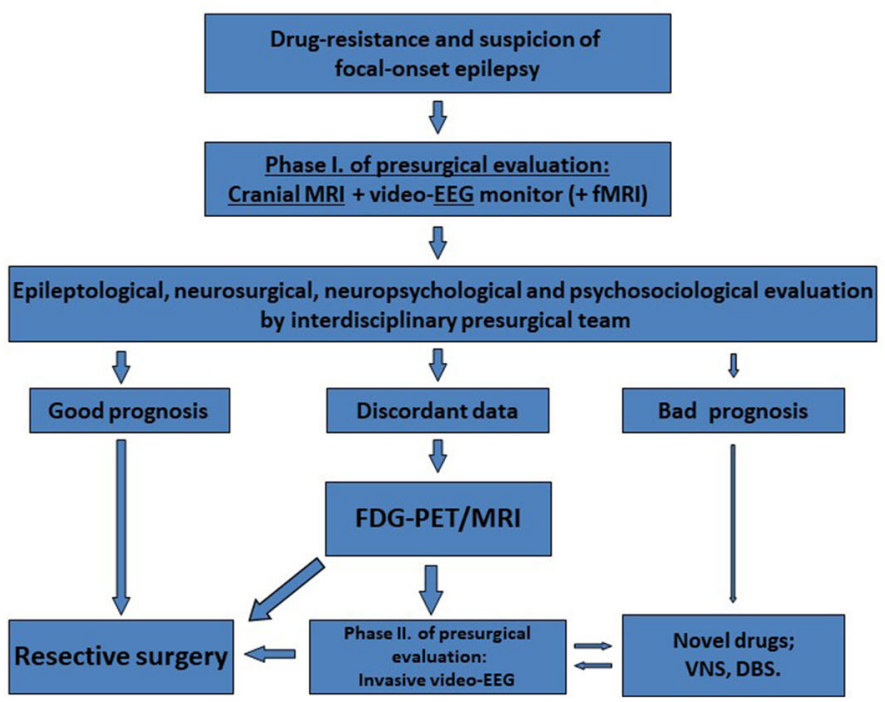

Fig. 1 An algorithm describing the steps of presurgical evaluation at our centers 
generated automatically. From the PET RAW DATA a $20 \mathrm{~min}$ and a $35 \mathrm{~min}$ static image dataset were produced. Attenuation-corrected and uncorrected transaxial slices were generated. For PET image reconstruction OPOSEM method was applied containing PSF correction (3 iterations, 21 subsets, $4 \mathrm{~mm}$ post-recon Gaussian filtering, $344 \times 344$ imaging matrix).

For MR imaging, the standard epilepsy protocol was used [25-28], comprising the following sequences: i) axial T2-weighted sequence used for PET attenuation correction (T2 UTE MRAC) $(\mathrm{TR}=11.94 \mathrm{~ms}$; TE1 $=0.07$ $\mathrm{ms}$, TE2 $=2.46 \mathrm{~ms}$, flip angle $=10^{\circ}$; voxel size: $1.6 \times 1.6 \times$ $1.6 \mathrm{~mm}$ ); ii) 2D T2-weighted axial TSE (slice thickness $4.0 \mathrm{~mm}$, TE/TR: $106 / 6000 \mathrm{~ms}, 150^{\circ}$ flip angle, matrix $358 \times 448$, voxel size: $0.5 \times 0.5 \times 4 \mathrm{~mm}$, scan duration 4 : $08 \mathrm{~s}$ ); iii) 2D T2-weighted coronal TSE (slice thickness $3.0 \mathrm{~mm}$, TE/TR: $89 / 6770 \mathrm{~ms}, 150^{\circ}$ flip angle, matrix $307 \times 348$, voxel size: $0.5 \times 0.5 \times 3 \mathrm{~mm}$, scan duration 3 : 04 s); iv) 2D T2-weighted coronal TSE FLAIR (slice thickness $3.0 \mathrm{~mm}$, TE/TR: $128 / 9000 \mathrm{~ms}, 120^{\circ}$ flip angle, matrix $192 \times 256$, voxel size: $0.9 \times 0.9 \times 3 \mathrm{~mm}$, scan duration 5:44s); v) axial diffusion-tensor imaging (DTI) (slice thickness $4.0 \mathrm{~mm}$, TE/TR: $95 / 3600 \mathrm{~ms}$, matrix $128 \times 128$, voxel size: $1.7 \times 1.7 \times 4 \mathrm{~mm}$, scan duration 3 : $59 \mathrm{~s}$ ); vi) axial T2* (slice thickness $4.0 \mathrm{~mm}$, TE/TR: 19.9 / $620 \mathrm{~ms}, 20^{\circ}$ flip angle, matrix $205 \times 256$, voxel size: $0.4 \times$ $0.4 \times 4 \mathrm{~mm}$, scan duration $2: 09 \mathrm{~s})$; vii) $3 \mathrm{D}$ T2-weighted sagittal gradient recalled echo (GRE) (slice thickness 1.0 $\mathrm{mm}$, TE/TR: $409 / 3200 \mathrm{~ms}, 120^{\circ}$ flip angle, matrix $261 \times$ 256 , voxel size: $0.5 \times 0.5 \times 1 \mathrm{~mm}$, scan duration $4: 43 \mathrm{~s}$ ); viii) $3 \mathrm{D}$ T2-weighted sagittal GRE FLAIR (slice thickness $1.0 \mathrm{~mm}$, TE/TR: $395 / 5000 \mathrm{~ms}, 120^{\circ}$ flip angle, matrix $261 \times 256$, voxel size: $0.5 \times 0.5 \times 1 \mathrm{~mm}$, scan duration 5 : $52 \mathrm{~s}$ ) and ix) 3D sagittal MPRAGE (slice thickness 1.0 mm, TE/TR: $2.98 / 2300 \mathrm{~ms}$, $9^{\circ}$ flip angle, matrix $240 \times$ 256 , voxel size: $1.0 \times 1.0 \times 1.2 \mathrm{~mm}$, scan duration 9:14 s).

MRI (both the prior studies and those with the accompanying PET) and PET studies were downloaded and blindly and separately re-interpreted, by two neuroradiologists (for MRI: PB and ZV) and nuclear medicine physicians (for PET: KB and ZT). The two MR studies were interpreted separately from each other by each of the neuroradiologists (PB, ZV). Finally, simultaneously acquired MRI and PET images were evaluated on fused images, and clinical decisions were done with these data.

New variables: MR status change, additional information provided by PET comparing to MRI and clinical decision according to $\mathrm{PET} / \mathrm{MRI}$ results

\section{MR status change}

We created five new categories to describe the changes:

nn: The patient was nonlesional prior to the study and he/she also remained nonlesional in this study. np: The patient was nonlesional prior to the study and changed to lesional in this study.

nc: The patient was suspect for lesional prior to the study but the lesion was not confirmed in this study. pp.: The patient was lesional prior to the study and the study confirmed the original lesion.

pp.+: The patient was lesional prior to the study and the study both confirmed the original lesion and found new epileptogenic lesion(s).

\section{Additional information provided by PET comparing to MRI (indicating the localisation of glucose hypometabolism in nonlesional case as well as in lesional case, related to the MRI-lesion)}

A. Positive, revealing unilateral area(s) of hypometabolism in a nonlesional case.

B. Positive, revealing bilateral area(s) of hypometabolism in a nonlesional case.

C. Positive, ipsilateral, related to the MRI-identified lesion in a lesional case.

D. Positive, ipsilateral, but not related to the MRIidentified lesion, pointing to new area(s) within the same hemisphere in a lesional case.

E. Positive, contralateral to MRI-lesion in a lesional case.

F. Positive, bilateral in lesional case in a lesional case. G. Negative.

\section{Clinical decisions according to PET/MRI results}

The clinical decisions made by a consensus of the two multidisciplinary epilepsy surgery teams at two tertiary academic medical centers were classified into six categories:

1. : Remained as iEEG candidate.

2. : Resective surgery is available instead of iEEG.

3. : Considered as not eligible for any further invasive procedures instead of iEEG.

4. : Became iEEG candidate instead of resective surgery.

5. : Considered as not eligible for any further invasive procedures instead of resective surgery

6. : Remained as candidate for resective surgery.

\section{Statistical analysis}

We applied the Chi-square independence test to determine if there is a significant relationship between "MRI status change" and "Additional information provided by PET comparing to MRI" and used Pearson residuals to highlight the most contributing between these category pairs. Because of the small sample size, we performed Fisher's exact test to confirm the result of the Chisquare test. 


\section{Results}

\section{Nonlesional group}

Hybrid PET/MRI examination revealed that 18 of 30 patients were found to have new specific epileptogenic MRI-lesion(s), while 29 of 30 patients had an abnormal FDG uptake. Two lesions were found in five patients. Hybrid PET/MRI helped to indicate resective surgery instead of iEEG monitoring in 2 patients due to congruent MRI, PET, semiological and EEG data; resective surgery was performed in both cases with Engel I outcome (for details, please see Table 1). In seven patients, hybrid PET/MRI enabled us to decide to avoid any further invasive diagnostic procedures due to multiple electroclinical and/or hypometabolic epileptic foci with MRI-negativity (6 patients) or negative imagery (both PET and MRI) results (1 patient). Of the remaining 21 patients referred to iEEG due to discordant electroclinical and PET/MRI results, in 11 cases one MRI-target was revealed; in 5 patients two potential epileptogenic lesions were found; while 5 cases remained nonlesional. In 3 of 11 patients of whom one MRI-target was revealed iEEG was performed concluding in resective surgery in 2 cases with Engel III and Engel IV outcome; the remaining case was considered as not operable and did not concede to perform DBS/VNS implantation.

Assessing the data comparing the structural highquality MRI from hybrid FDG PET/MRI ("MRI status change") with the information providing the combination of glucose hypometabolism with structural data ("Additional information provided by PET comparing to MRI"), the Chi-square independence test and Fisher's exact test showed a significant association $(p<10 \mathrm{e}-6$ and $\mathrm{p}<10 \mathrm{e}-10$, respectively). The Pearson residuals suggested that the group "np" (the patients were nonlesional prior to the study and changed to lesional in this study) and group "A" (PET revealed unilateral area(s) of hypometabolism in nonlesional cases) have a strong positive association as well as between group "nn" (patients were nonlesional prior to the study and they also remained nonlesional in this study) and group "B" (PET revealed bilateral area(s) of hypometabolism in nonlesional cases).

\section{Lesional group}

Two patients became eligible for resective surgery, because of concordant electroclinical and hybrid FDGPET/MRI results, which confirmed the MRI-lesion visualized prior to this study. In one patient any further invasive investigation was found to be contraindicated due to discordant electroclinical and PET data; but more importantly, because of altered MRI-status (nonlesional).

iEEG was planned in 27 patients, of whom three patients became eligible for resective surgery because of concordant hybrid FDG-PET/MRI results and electroclinical data; resective surgery was performed with Engel I outcome in 1 case and Engel II outcome in 2 cases (for details, please see Table 2).

Six of the remaining 27 patients proved to be inoperable instead of iEEG, 4 of these patients were found not to be confirmed lesional. In 3 patients, any further invasive procedure was contraindicated. Eighteen patients remained candidates for iEEG due to discordant electroclinical and FDG-PET/MRI results. In 6 of 18 patients iEEG was already performed concluding in resective surgery in all cases with Engel I (3 cases) and Engel II (3 cases) outcome.

Statistical analysis of the data comparing the structural high-quality MRI from hybrid FDG PET/MRI with the information providing the combination of glucose hypometabolism with structural data did not reveal strong association in any case in lesional group.

\section{Discussion}

In the case of drug-resistant focal-onset epilepsy, the most important issue in the algorithm of the decisionmaking is to judge whether a drug-resistant epilepsy patient is eligible for (1) resective surgery, (2) iEEG monitoring, or, (3) not eligible for any further invasive procedures $[7,8]$.

PET/MRI coregistration has long been utilized in epilepsy centers and has been useful to guide a second look at MRI previously reported as nonlesional, thus guiding decision-making [17]. In an earlier publication, PET/ MRI coregistration helped to find obvious lesion in 6 of 10 nonlesional drug-resistant epilepsy patients [18]. In a pediatric study, 31 consecutive pediatric nonlesional epilepsy patients were reported, of whom nine showed subtle pathologic abnormalities after second MRI-reading guided by PET/MRI coregistration [19]. In another study, 35 consecutive epilepsy patients with refractory focal epilepsy were investigated: structural MRI showed no lesion in 15 patients, of whom PET/MRI coregistration detected hypometabolism in 7 cases that was undetected on PET alone [20]. In a recent paper, 103 consecutive epileptic patients with FCD type 2 were reported, of whom 61 patients were lesional, while 42 cases were dubious or negative. The additional value of PET/MRI coregistration in these 42 patients was predominant, because MRI localized FCD type 2 in 35 of 42 patients [21].

Here we report the role of hybrid FDG-PET/MRI on the decision-making workflow. Thus, in the present study, findings related to the changes in possible decisions of the presurgical team were analyzed in detail with respect to separate imaging results (FDG-PET and MRI) in both lesional and nonlesional epilepsy patients.

Our main finding is that hybrid FDG-PET/MRI decidedly influenced the decision-making of the presurgical team significantly. Its cardinal effect was the 


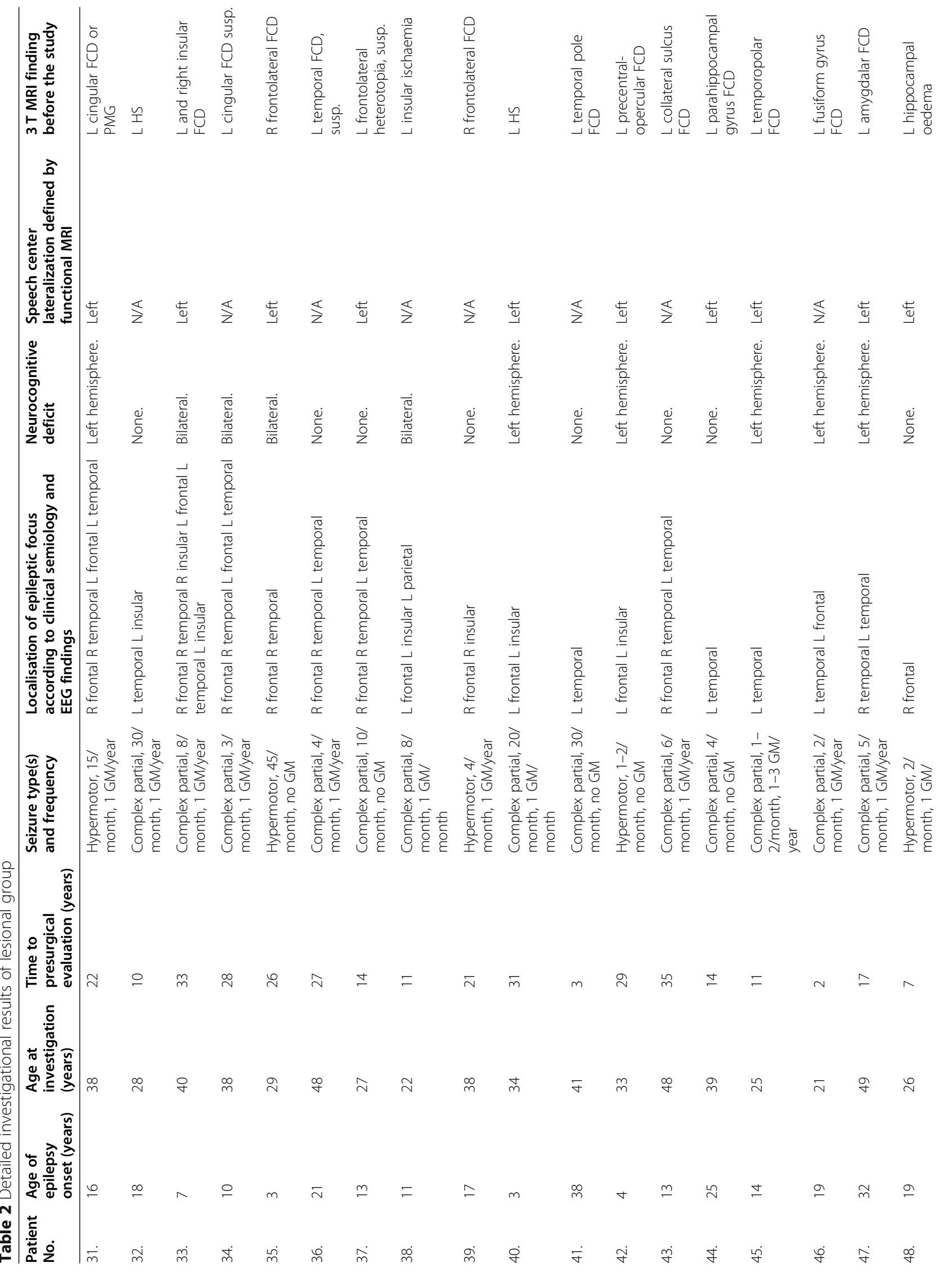




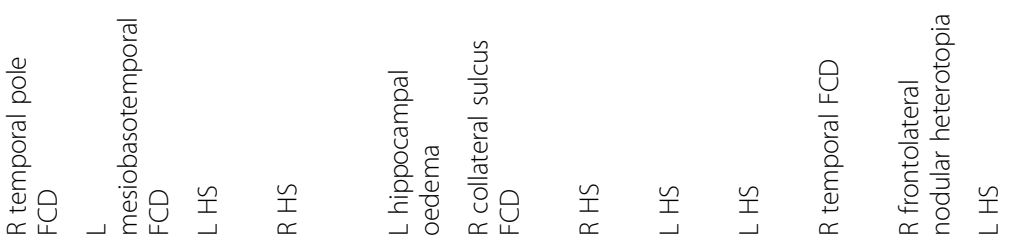

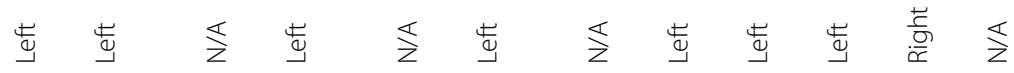

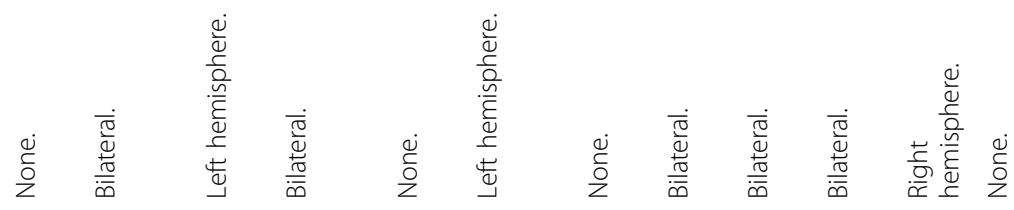

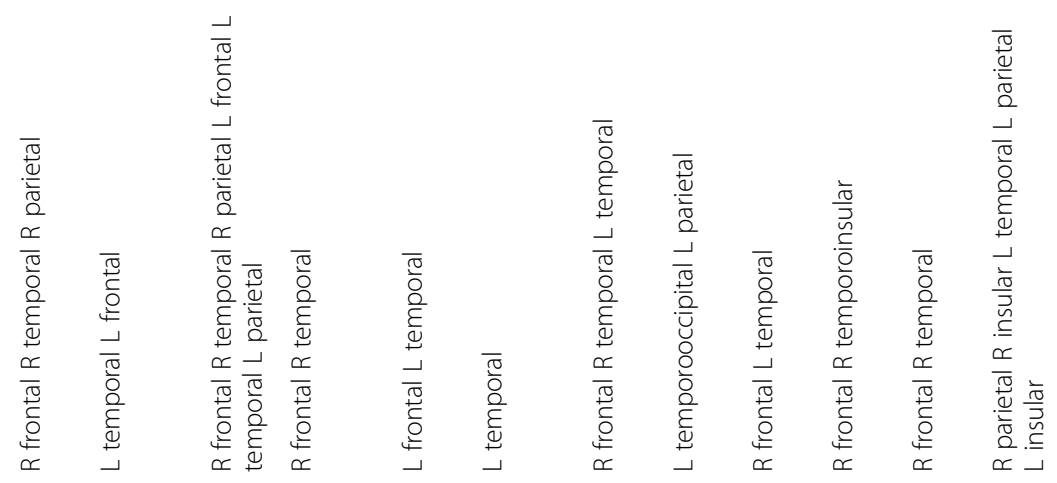

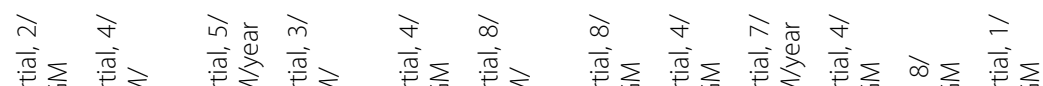

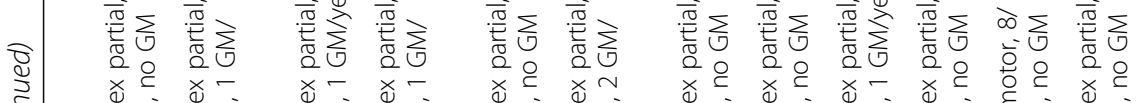

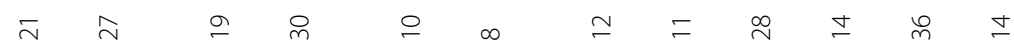

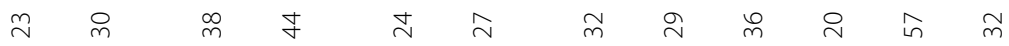

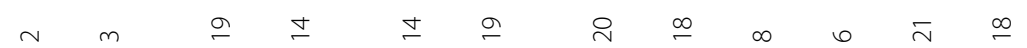

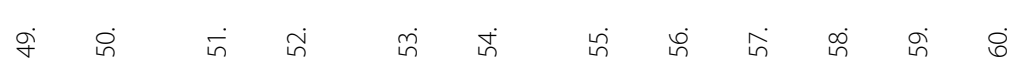




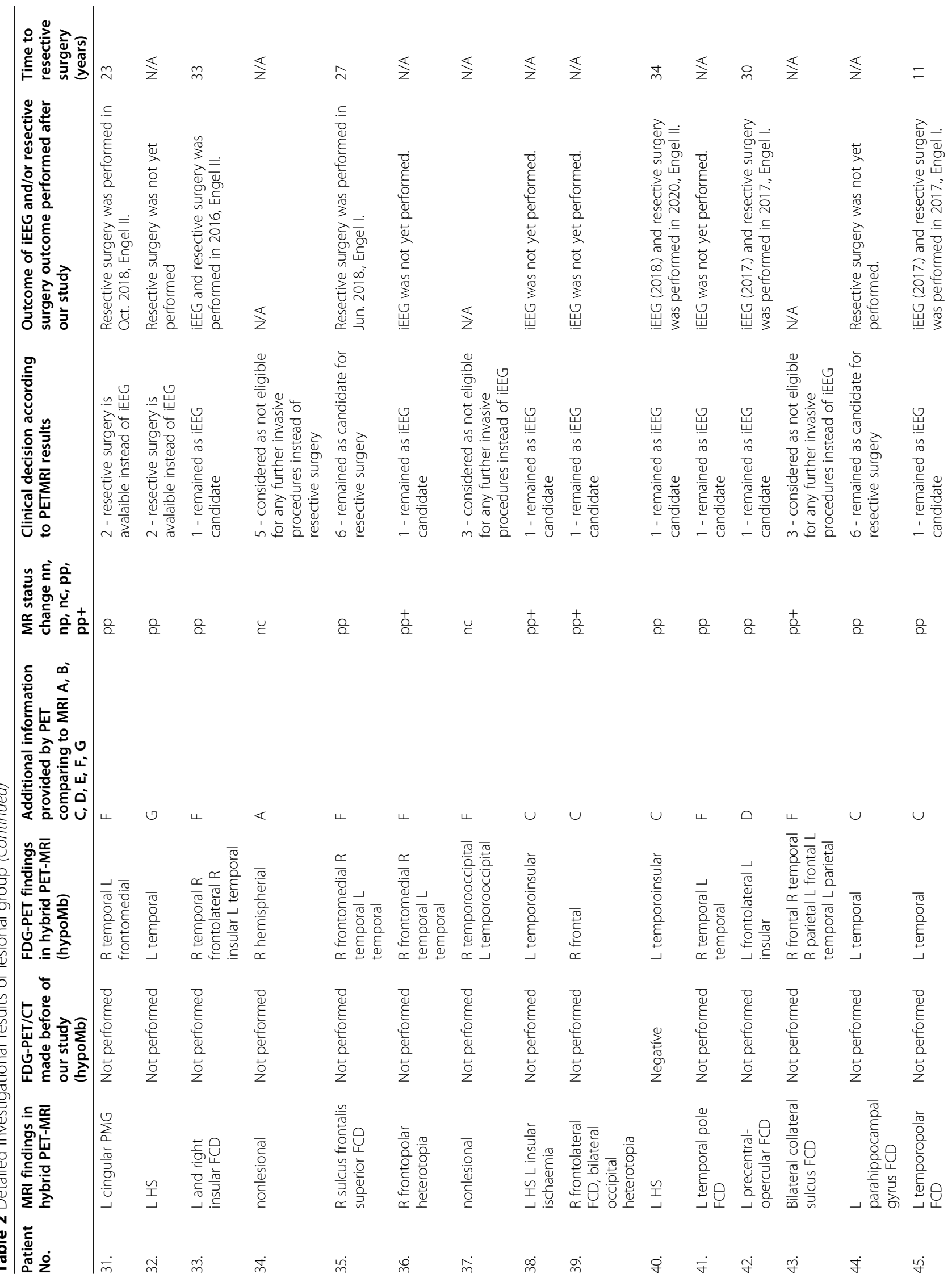




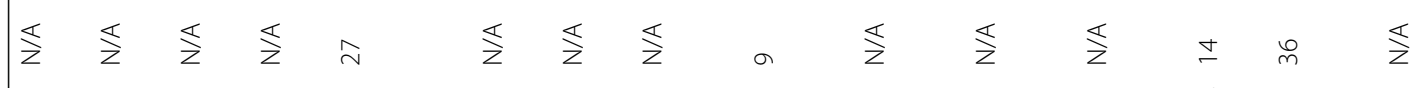

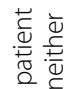

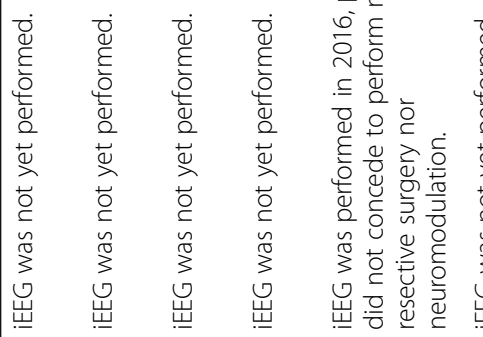

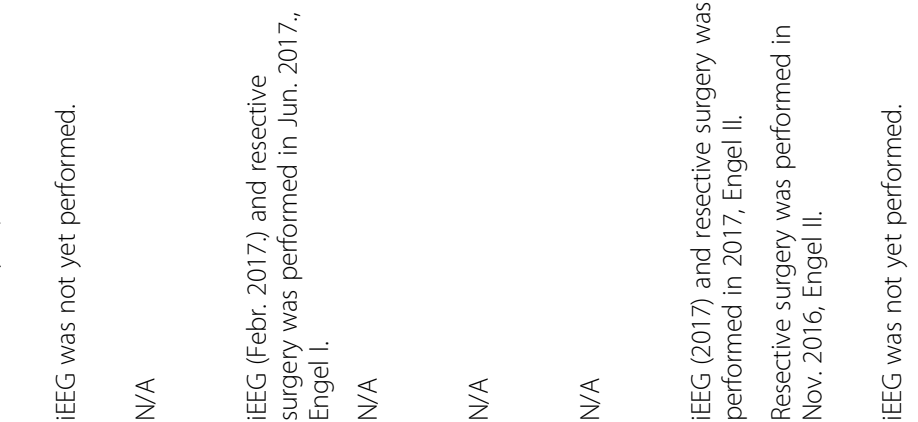

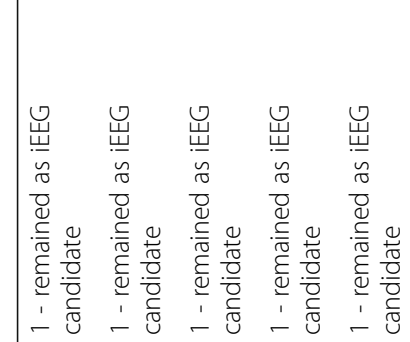

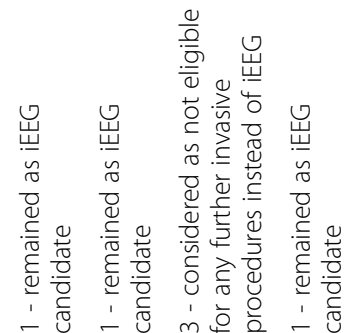

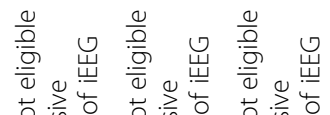

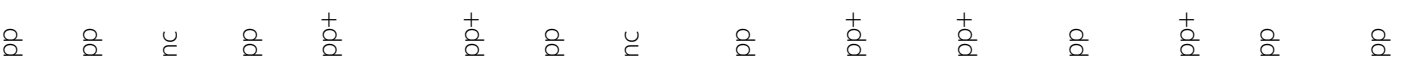

$\sqcup \cup \infty \quad \sqcup$

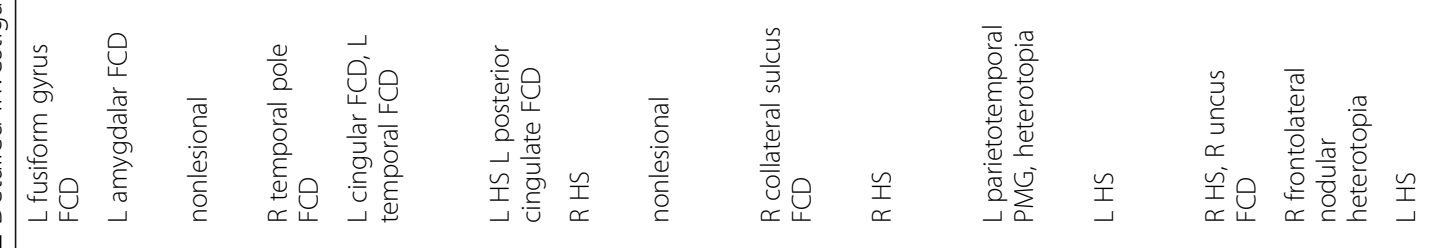


17/06/2015 06:02:55 Patient 19, Birthdate 18 December 1997
Hp filter: $0.16 \mathrm{~Hz}$ Lp filter: $100.0 \mathrm{~Hz}$ Gain: $100 \mu \mathrm{V} / \mathrm{cm}$ Notch: Yes
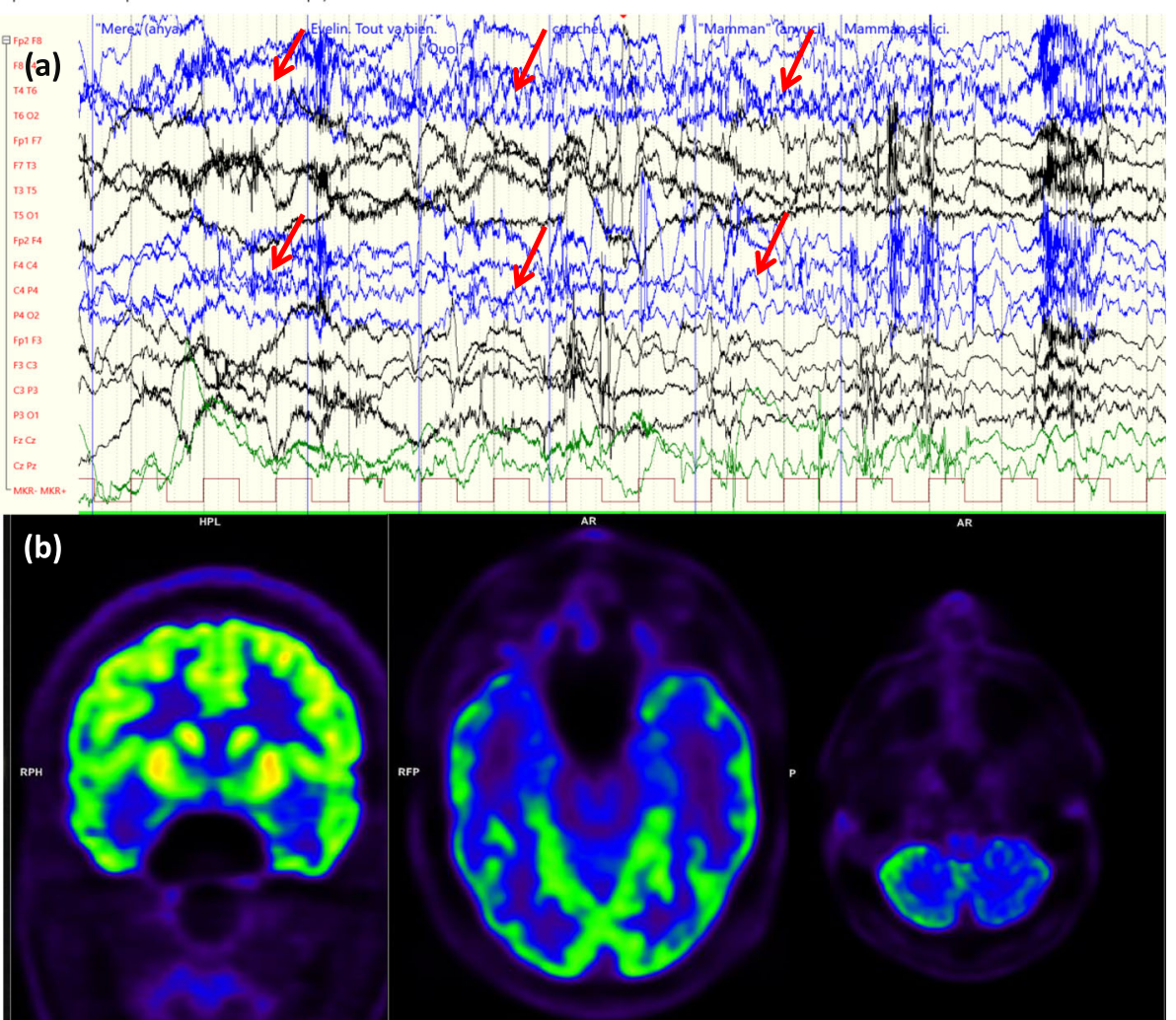

15/05/2019 07:56:50 Patient 24, Birthdate 03 July 1973

Hp fiterf $0.0 \mathrm{~Hz}$ Lp filter: $800.0 \mathrm{~Hz}$ Gain: $800 \mu \mathrm{V} / \mathrm{cm}$ Notch: Yes

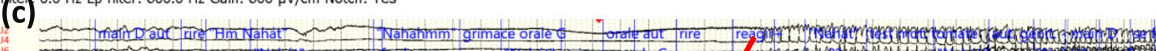

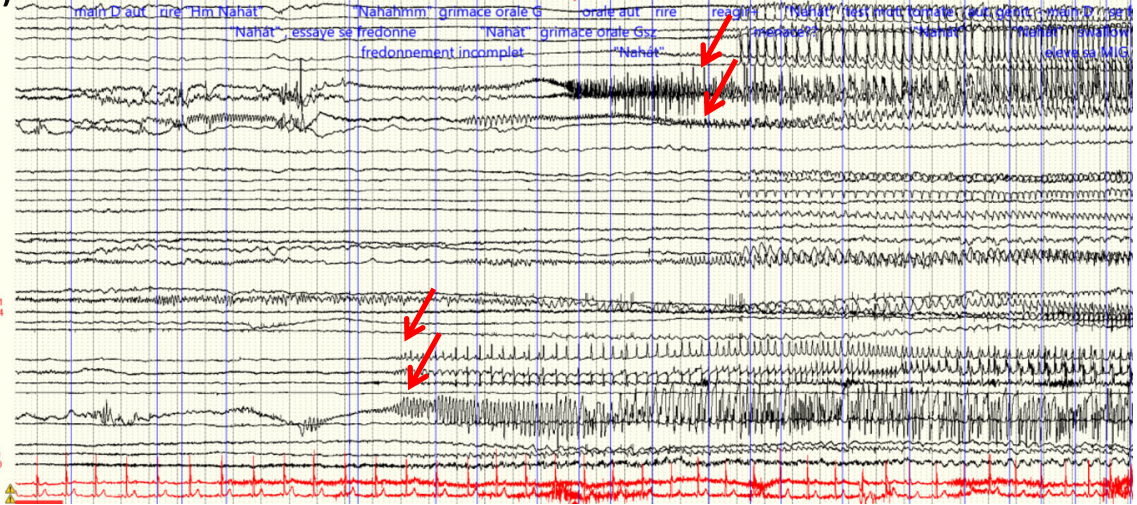

Fig. 2 (Case 28, Table 1, group nn, decision type 1.): A drug-resistant epileptic patient with the electroclinical features of humming epilepsy. a Video-EEG monitoring: during one of his habitual seizure, a right frontotemporal seizure activity was registered (red arrows). Originally, he was nonlesional and this MRI-status did not change yet after this study. $\mathbf{b}$ and $\mathbf{c}$ 18F-FDG PET and PET/MRI presented a bitemporal hypometabolism with a right predominance (red boxes) and $\mathbf{d}$ a left cerebellar hypometabolism (red box). $\mathbf{c}$ This patient remained as an iEEG candidate. iEEG monitor has been performed and showed a bitemporal seizure activity with a left side onset (red arrows, left side of the figure), a left-right propagation in between a 10-s interval (red arrows, right side of the figure), which was remote-controlled by a possible left orbitofrontal seizure onset zone. The patient did not allow neither a second iEEG intervention, nor VNS or DBS implantation 

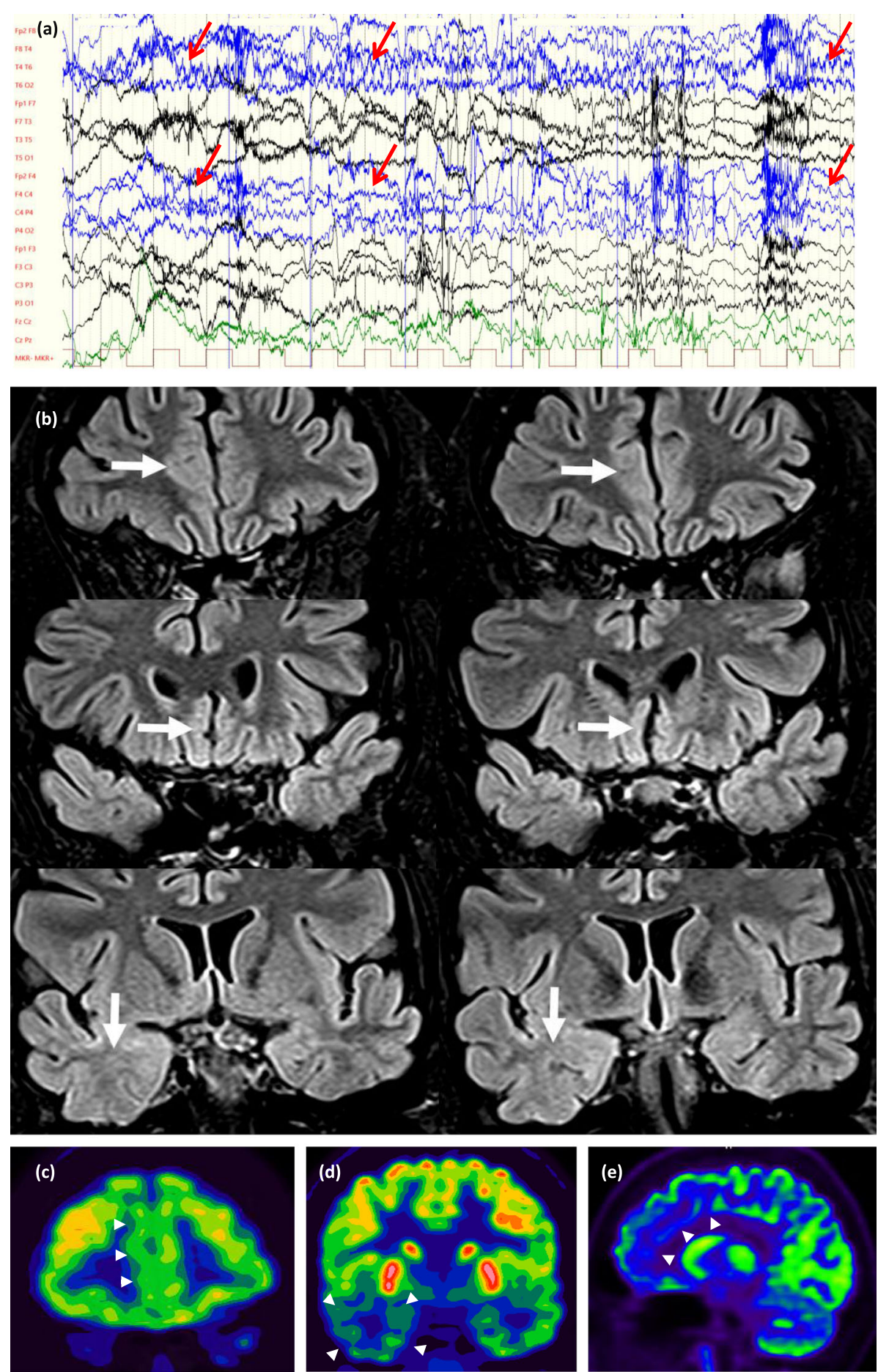

Fig. 3 (Case 24, Table 1, group np, decision type 1.) A drug-resistant epileptic patient with the electroclinical features of a right frontotemporal epilepsy. a During video-EEG monitoring, her habitual hypermotor seizure with a right frontotemporal seizure activity was registered (red arrows). Originally, she was nonlesional and became lesional in this study. b Coronal FLAIR images: white arrows show possible focal cortical dysplasia in the right anterior cingulate cortex (upper row), in the medial cortex of the right straight gyrus (middle row), and the mildly increased signal intensity and blurred cortex-white matter interface in the right temporal lobe (lower row) can be seen. 18F-FDG PET and PET/MRI presented $\mathbf{c}$ and $\mathbf{e}$ a hypometabolism in the right mesiofrontal region (white arrowheads), $\mathbf{d}$ as well as in the right temporal lobe (white arroewheads). This patient remained as iEEG candidate; iEEG monitoring has not yet been realised 
15/05/2012 16:04:18 Patient 11, Birthdate 01 October 1958
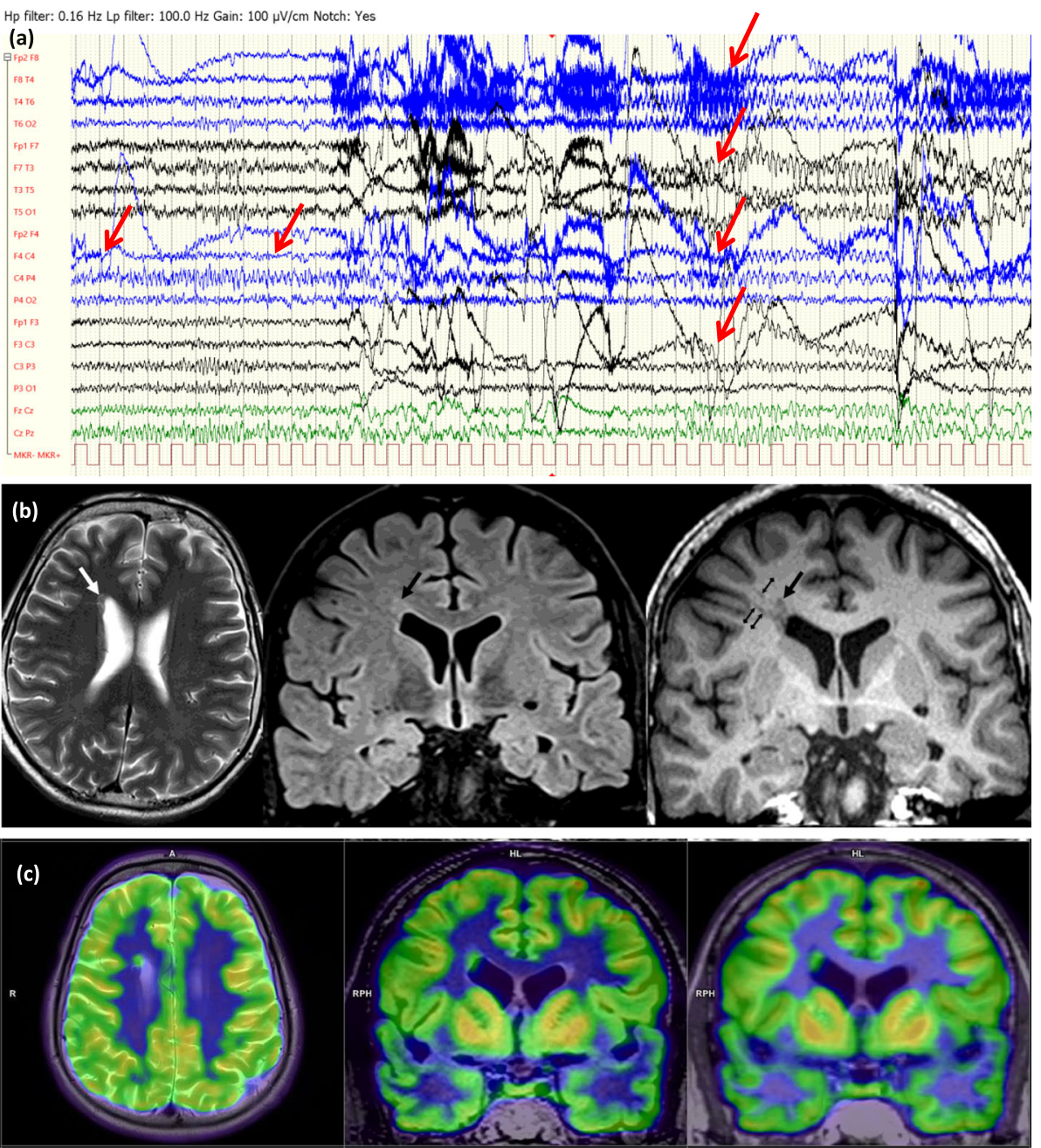

Fig. 4 (Case 59, Table 2, group pp., decision type 2.): A drug-resistant epileptic patient with the electroclinical features of a right frontal epilepsy. a Video-EEG monitoring revealed his habitual seizure, a right frontocentral seizure activity was seen, which rapidly became bilateral (marked with red arrows). Concordantly, cranial MRI showed a nodular heterotopia in the right inferior frontal gyrus. b Axial T2 (left), coronal FLAIR (middle) and coronal T1 MPR (right) images. The white arrow on the T2 image and the large black arrows on the FLAIR and T1 images show focal nodular subependymal grey matter heterotopia. The small black arrows on the coronal T1 MPR image (right) show probable migrational bands. c Exceptionally compared to the other cases, during 18F-FDG PET and PET/MRI, a circumscribed FDG accumulation reaching the intensity of cortical tracer uptake (and highly exceeding white matter uptake) can be observed, identically to the right periventricular heterotopia. In this case, resective surgery became available instead of iEEG. Because the patient was left-handed, fMRI and also Wada-test were performed and they proved that in this case, active Broca region is localized in the right hemisphere. Thus, resective surgery was performed in awake state and finally, only a partial resection was possible. After the resective surgery, patient had much shorter ( $1-3 \mathrm{~s}$ long) seizures

increased sensitivity of brain MRI in $60 \%$ of nonlesional patients, which is a principal component in judging the chance for seizure-freedom (nonlesional cases: 20-65\% vs. lesional cases: 60-90\%) [10, 11].

In an earlier pilot study using hybrid PET/MRI, 11 epileptic patients were investigated by FDG-PET/MRI without gross structural abnormalities that could interfere with image processing. Unfortunately, it is not clear from this publication, whether or not new structural lesions were found [23].
In another pilot hybrid FDG-PET/MRI study, of the twenty-nine patients assessed who underwent epilepsy surgery evaluation, in four cases new structural MR lesions were detected with the aid of FDGPET findings, and one patient showed a new abnormal hypometabolism without any MRI abnormality. All new FDG-PET/MR lesions were clinically significant with concordant EEG and/or SPECT results as potential epileptic foci [24]. Recently, the same research group reported that hybrid FDG-PET/MR 

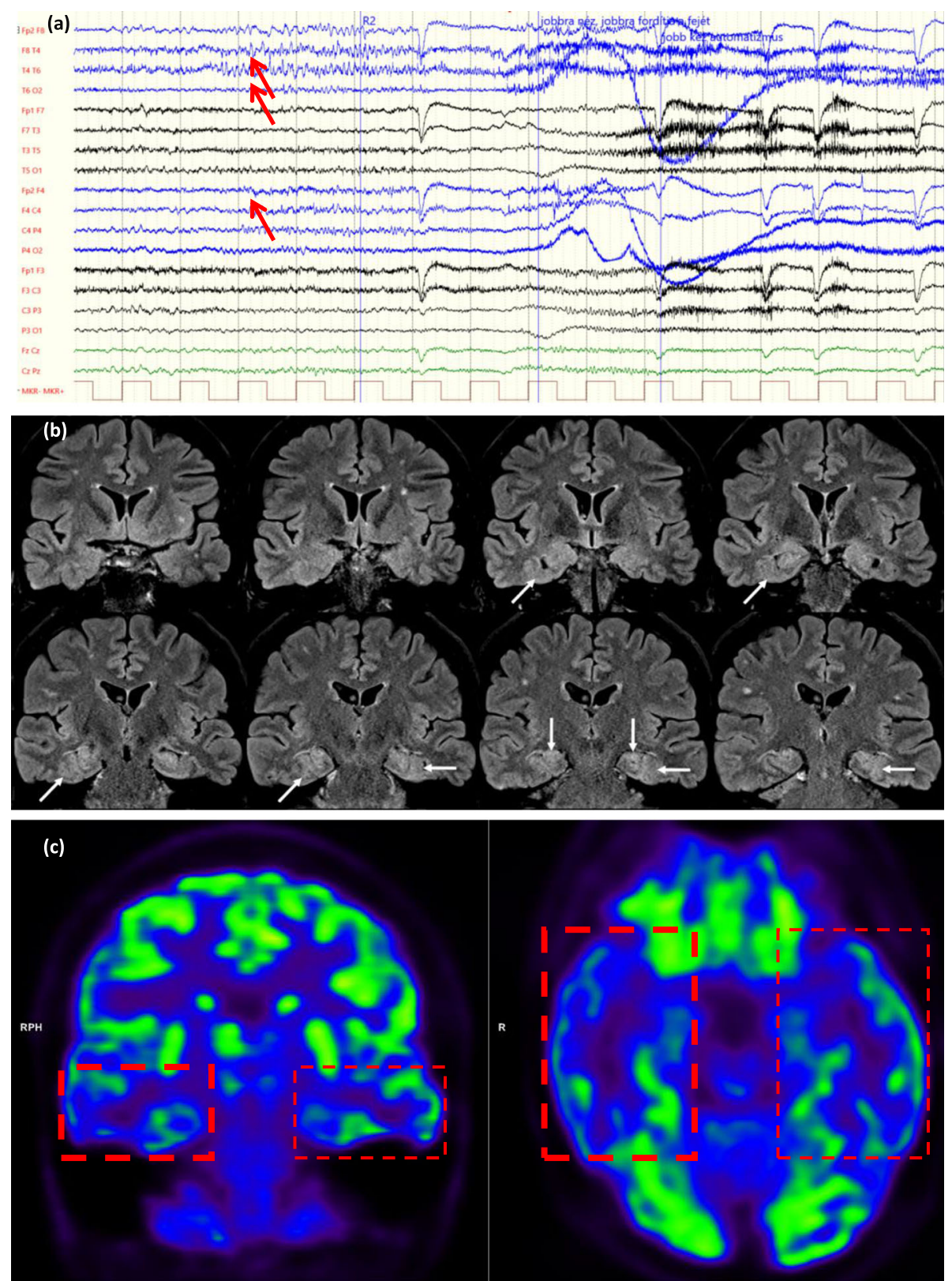

Fig. 5 (Case 43, Table 2, group pp.+, decision type 3.) A drug-resistant epileptic patient with the electroclinical features of a bitemporal lobe epilepsy. a Video-EEG monitoring. During her habitual seizure, a right frontotemporal seizure rapid activity was seen (marked with red arrows). Meanwhile, original cranial MRI (made before this study) showed an FCD along the left collateral sulcus. b Cranial MRI made in this study (coronal FLAIR images): horizontal arrows show the originally detected FCD along the left collateral sulcus while the oblique arrows show the newly observed FCD along the right collateral sulcus. The vertical arrows show the typical configuration of bilateral hippocampal malrotation, while $\mathbf{c}$ and $\mathbf{d}$ 18F-FDG PET and PET/MRI presented a hypometabolism in the right and left frontotemporal lobe, with a right predominance (red boxes). In summary, this patient was considered as not eligible for any further invasive procedures instead of iEEG

identified new structural or functional lesions in 10 of 74 patients [22].

Our study aimed to clarify the possible role of hybrid FDG-PET/MRI on decision-making in drugresistant partial-onset epilepsy patients as well as to compare this effect with earlier PET/MRI coregistration studies.

\section{Nonlesional group}

In our study, the hybrid FDG-PET/MRI revealed a new morphological lesion in 18 patients and PET hypometabolism in 29 patients within the nonlesional group. In this patient cohort, PET revealed unilateral area(s) of hypometabolism. However, PET revealed bilateral area(s) of hypometabolism in those patients who were 
nonlesional prior to the study and also remained nonlesional in this study. These two correlations were proved to be statistically significant.

Due to hybrid FDG-PET/MRI results, resective surgery was indicated instead of iEEG monitoring in 2 cases with an Engel I outcome; hybrid FDG-PET/MRI results helped to avoid any further invasive diagnostic procedures in 7 patients. The remaining 21 patients were referred to iEEG. In 16 of the remaining 21 patients, novel specific epileptogenic MRI-lesion(s) were revealed, proposing potential target(s) for iEEG monitoring, hopefully increasing the chance of successful identification of the epileptogenic zone. Three of them were underwent iEEG and 2 of them resective surgery with Engel III and IV outcome.

As we showed in Methods section, (beyond better image quality/resolution) a major difference was the application of 3D FLAIR sequence which was lacking in the earlier imaging protocol. This might in part explain the newly identified specific epileptogenic lesions in a significant proportion of the nonlesional group. Nine of these 18 patients showed the newly detected lesions exclusively on the 3D FLAIR images. Another possible explanation is the growing body of experience of our neuroradiologists together with the PET-readings (and these data were new information for them) and thus their increased sensitivity. Finally, the quality of MRI images deriving from the new hybrid PET/MRI systems was much better. These factors combined might explain the $60 \%$ difference (18 patients/30 nonlesional patients).

Moreover, in nine of the 30 cases, findings of hybrid FDG-PET/MRI resulted in a significant change in decision-making (iEEG monitoring, resective surgery or not eligible for any further invasive procedures) (Figs. 2 and 3).

\section{Lesional group}

Hybrid FDG-PET/MRI disclosed at least one new morphological lesion in 9 patients and glucose hypometabolism in 30 patients within the lesional group.

Four patients found to be nonlesional in this study. In 17 cases the original lesion was confirmed. As we mentioned above, the major difference was the application of 3D FLAIR sequence which was lacking in the earlier imaging protocol, which might in part explain the newly identified specific epileptogenic lesions in the lesional group.

Hybrid FDG-PET/MRI has also significantly changed the original therapeutic plans in the lesional group. Three patients became eligible for resective surgery two of them were operated with an Engel II outcome. Six patients were considered as not eligible for any further invasive procedure, and 18 cases still remained as candidates for iEEG. iEEG was already performed in 6 of 18 patients concluding in resective surgery with Engel I outcome in 3 cases and Engel II outcome in remaining 3 cases. Two patients remained as candidates for resective surgery - one of them was operated with an Engel I outcome. In both groups the new anatomical or functional lesions were found to be clinically significant.

In the lesional group, hybrid FDG-PET/MRI investigation altered the the epileptologist's original decision in 10 of 30 cases: resective surgery, iEEG, or not eligible for any further invasive procedures (Figs. 4 and 5).

\section{Conclusions}

Our study was undertaken to evaluate the potential improvement on decision-making using a hybrid FDGPET/MRI scanner in epilepsy surgery algorithm, compared to separate $3 \mathrm{~T}$ MRI and electroclinical data. The results of hybrid FDG-PET/MRI significantly altered the original plans in 19 of 60 cases. In the nonlesional group, in 18 cases, novel specific epileptogenic MRI-lesions were revealed, proposing potential targets for iEEG monitoring, thus hopefully increasing the chance of successfully identifying the epileptogenic zone in the most difficult epilepsy patients cohort.

\section{Abbreviations}

DBS: Deep brain stimulation; DTI: Diffusion-tensor imaging; DWI: Diffusionweighted imaging; [18F] FDG: Fluorine-18 fluoro-2-deoxyglucose;

FLAIR: Fluid-attenuated inversion recovery; GRE: Gradient recalled echo; iEEG: Invasive EEG; MPRAGE: Magnetization Prepared Rapid Acquisition Gradient Echo; SWI: Susceptibility weighted imaging; TOF: Time-of-flight; TSE: Turbospin-echo; UTE: Ultrashort echo time; VNS: Vagus nerve stimulation; nn: The patient was nonlesional prior to the study and he/she also remained nonlesional in this study; $\mathrm{np}$ : The patient was nonlesional prior to the study and changed to lesional in this study; nc: The patient was suspect for lesional prior to the study but the lesion was not confirmed in this study; pp.: The patient was lesional prior to the study and the study confirmed the original lesion; pp. + : The patient was lesional prior to the study and the study both confirmed the original lesion and found new epileptogenic lesion(s); A.: Positive, revealing unilateral area(s) of hypometabolism in a nonlesional case; B.: Positive, revealing bilateral area(s) of hypometabolism in a nonlesional case; C.: Positive, ipsilateral, related to the MRI-identified lesion in a lesional case; D.: Positive, ipsilateral, but not related to the $\mathrm{MRI}$-identified lesion, pointing to new area(s) within the same hemisphere in a lesional case; E.: Positive, contralateral to MRI-lesion in a lesional case; F.: Positive, bilateral in lesional case in a lesional case;

G.: Negative; 1.: Remained as iEEG candidate; 2 .: Resective surgery is available instead of iEEG; 3.: Considered as not eligible for any further invasive procedures instead of iEEG; 4.: Became iEEG candidate instead of resective surgery; $5 .:$ Considered as not eligible for any further invasive procedures instead of resective surgery; 6 .: Remained as candidate for resective surgery

\section{Acknowledgements}

This article was supported by the Hungarian Brain Research Program (20171.2.1-NKP-2017-00002), NKFIH EFOP-3.6.2-16-2017-00008, and GINOP-2.3.3-152016-00032 government-based funds. Our research was financed by Dr. József Baka Diagnostic, Radiation Oncology, Research and Teaching Center, University of Kaposvár and MEDICOPUS Healthcare Provider and Public

Nonprofit Ltd., Kaposvár, PET Center, University of Kaposvár.

\section{Authors' contributions}

MT: patient examination; semiology; study design, manuscript preparation. PB: MRI expert, evaluation of MRIs. ZT: PET planning and analysis. KB: initiator of the study, study design, PET planning and analysis, manuscript correction. JL: patients preparation for PET-MRI examination; and follow-up. ME: data analysis, statistics, study design. IR: initiator of the study, ensuring the PET/ MRI facility, organization of the imaging examinations; ethical permission. JJ: study design, semiology; manuscript preparation. TD: initiator of the study, 
study design, writing the application for ethical permission, manuscript preparation. ZsH: patients analysis. PH: senior epileptologist, patients analysis, semiology. VJ: patients analysis, semiology. CsGy: patients analysis, semiology. BB: patients analysis, semiology. DK: patients analysis, semiology. $\mathrm{RH}$ : patients analysis, semiology. FN: patients preparation for PET/MRI examination; and follow-up. AK: patients analysis, semiology. ZsJ: patients analysis, semiology. AU: patients analysis, semiology. KH: manuscript design and correction. J: manuscript design and correction. EP: manuscript preparation. AF: PET analysis. DF: patient analysis, semiology, study design, manuscript preparation. ZsV: expert of MRI analysis, study design; manuscript preparation. The author(s) read and approved the final manuscript.

\section{Funding}

This article was supported by the Hungarian Brain Research Program (20171.2.1-NKP-2017-00002), NKFIH EFOP-3.6.2-16-2017-00008, and GINOP-2.3.3-152016-00032 government-based funds covering the costs of analysis, and interpretation of data. Our research was financed by Dr. József Baka Diagnostic, Radiation Oncology, Research and Teaching Center, University of Kaposvár and MEDICOPUS Healthcare Provider and Public Nonprofit Ltd., Kaposvár, PET Center, University of Kaposvár, covering the costs of the design of the study and collection and analysis of data (approved by Scientific Research Ethics Committee of the Medical Research Council of Hungary, 008899/2016/ OTIG)

\section{Availability of data and materials}

The datasets used and/or analysed during the current study are available from the corresponding author on reasonable request.

\section{Declarations}

\section{Ethics approval and consent to participate}

We confirm that we have read the Journal's position on issues involved in ethical publication and affirm that this report is consistent with those guidelines. This study was approved by Scientific Research Ethics Committee of the Medical Research Council of Hungary (No. 008899/2016/OTIG). Written informed consent was obtained from all participants.

\section{Consent for publication}

Not applicable.

\section{Competing interests}

Neither of the authors has any conflict of interest concerning the materials or methods used in this study or the findings specified in this paper to disclose.

\section{Author details}

${ }^{1}$ Department of Neurology, Medical School, University of Pécs, Rét u. 2, Pécs $\mathrm{H}-7623$, Hungary. ${ }^{2}$ Department of Medical Imaging, Semmelweis University, Balassa út 6, Budapest H-1083, Hungary. ${ }^{3}$ Dr. József Baka Diagnostic, Radiation oncology, Research and Teaching Center, Somogy County Moritz Kaposi Teaching Hospital, Guba Sándor u. 40, Kaposvár H-7400, Hungary. ${ }^{4}$ MEDICOPUS Healthcare Provider and Public Nonprofit Ltd., Somogy County Moritz Kaposi Teaching Hospital, Guba Sándor u. 40, Kaposvár H-7400, Hungary. ${ }^{5}$ PET/CT Ambulance, National Institute of Oncology, Ráth György u.7-9, Budapest H-1122, Hungary. ${ }^{6}$ Division of Nuclear Medicine and Translational Imaging, Department of Medical Imaging, Faculty of Medicine, University of Debrecen, Nagyerdei krt. 98, Debrecen H-4032, Hungary. ${ }^{7}$ MTA-PTE Clinical Neuroscience MRI Research Group, Ifjúság u. 20, Pécs $\mathrm{H}-7624$, Hungary. ${ }^{8}$ Department of Neurosurgery, Medical School, University of Pécs, Rét u. 2, Pécs H-7623, Hungary. ${ }^{9}$ National Institute of Clinical Neurosciences, Amerikai út 57, Budapest H-1145, Hungary. ${ }^{10}$ Epihope Non-Profit Kft, Szilágyi Erzsébet fasor 17-21, Budapest 1026, Hungary. ${ }^{11}$ Department of Neurology, Somogy County Moritz Kaposi Teaching Hospital, Sándor u. 40, Guba H-7400, Hungary. ${ }^{12}$ Epilepsy and Sleep Center, Fukuoka Sanno Hospital, 3-6-45, Momochihama, Sawara-ku, Fukuoka 814-0001, Japan. ${ }^{13}$ Department of Functional Neurology and Epileptology, Hospices Civils de Lyon, Hospital for Neurology and Neurosurgery Pierre Wertheimer, 59 Boulevard Pinel, 69500 Lyon, France.
Received: 28 October 2020 Accepted: 12 August 2021

Published online: 18 September 2021

\section{References}

1. Bell GS, Sander JW. The epidemiology of epilepsy: the size of the problem. Seizure. 2001;10(4):306-16. https://doi.org/10.1053/seiz.2001.0584.

2. Ekman M, Forsgren L. Economic evidence in epilepsy: a review. Eur J Health Econ. 2004;5(SUPPL. 1):36-42.

3. Banerjee PN, Filippi D, Allen HW. The descriptive epidemiology of epilepsy-a review. Epilepsy Res. 2009;85(1):31-45. https://doi.org/10.1016/j.eplepsyres.2 009.03.003.

4. Marson A, Jacoby A, Johnson A, Kim L, Gamble C, Chadwick D. Immediate versus deferred antiepileptic drug treatment for early epilepsy and single seizures: a randomised controlled trial. Lancet. 2005;365(9476):2007-13. https://doi.org/10.1016/S0140-6736(05)66694-9.

5. Mula M, Cock HR. More than seizures: improving the lives of people with refractory epilepsy. Eur J Neurol. 2015;22(1):24-30. https://doi.org/10.1111/ ene.12603.

6. Remy $\mathrm{S}$, Beck H. Molecular and cellular mechanisms of pharmacoresistance in epilepsy. Brain. 2006;129(1):18-35. https://doi.org/10.1093/brain/awh682.

7. De Tisi J, Bell GS, Peacock JL, McEvoy AW, Harkness WF, Sander JW, et al. The long-term outcome of adult epilepsy surgery, patterns of seizure remission, and relapse: a cohort study. Lancet. 2011;378(9800):1388-95. https://doi.org/10.1016/S0140-6736(11)60890-8.

8. Taussig D, Montavont A, Isnard J. Invasive EEG explorations. Neurophysiol Clin. 2015;45(1):113-9. https://doi.org/10.1016/..neucli.2014.11.006.

9. Kwon CS, Neal J, Telléz-Zenteno J, Metcalfe A, Fitzgerald K, HernandezRonquillo $L$, et al. Resective focal epilepsy surgery - has selection of candidates changed? A systematic review. Epilepsy Res. 2016;122:37-43. https://doi.org/10.1016/j.eplepsyres.2016.02.007.

10. Téllez-Zenteno JF, Ronquillo $L H$, Moien-Afshari F, Wiebe S. Surgical outcomes in lesional and non-lesional epilepsy: a systematic review and meta-analysis. Epilepsy Res. 2010;89(2-3):310-8. https://doi.org/10.1016/j.eplepsyres.2010.02.007.

11. Noe K, Sulc V, Wong-Kisiel L, Wirrell E, Van Gompel JJ, Wetjen N, et al. Longterm outcomes after nonlesional extratemporal lobe epilepsy surgery. JAMA Neurol. 2013;70(8):1003-8. https://doi.org/10.1001/jamaneurol.2013.209.

12. Alarcón G, Valentín A, Watt C, Selway RP, Lacruz ME, Elwes RDC, et al. Is it worth pursuing surgery for epilepsy in patients with normal neuroimaging? I Neurol Neurosurg Psychiatry. 2006;77(4):474-80. https://doi.org/10.1136/jnnp.2005.077289.

13. Bien CG, Raabe AL, Schramm J, Becker A, Urbach H, Elger CE. Trends in presurgical evaluation and surgical treatment of epilepsy at one Centre from 1988-2009. J Neurol Neurosurg Psychiatry. 2013;84(1):54-61. https:// doi.org/10.1136/jnnp-2011-301763.

14. Chapman K. Seizure outcome after epilepsy surgery in patients with normal preoperative MRI. J Neurol Neurosurg Psychiatry. 2005;76(5):710-3. https:// doi.org/10.1136/jnnp.2003.026757.

15. Duncan JS. Imaging in the surgical treatment of epilepsy. Nat Rev Neurol. 2010;6(10):537-50. https://doi.org/10.1038/nrneurol.2010.131.

16. Jayakar P, Gotman J, Harvey AS, Palmini A, Tassi L, Schomer D, et al. Diagnostic utility of invasive EEG for epilepsy surgery: indications, modalities, and techniques. Epilepsia. 2016;57(11):1735-47. https://doi.org/1 0.1111/epi.13515.

17. Lee KK, Salamon N. [18F] fluorodeoxyglucose-positron-emission tomography and MR imaging coregistration for presurgical evaluation of medically refractory epilepsy. Am J Neuroradiol. 2009;30(10):1811-6. https://doi.org/1 0.3174/ajnr.A1637.

18. Salamon N, Kung J, Shaw SJ, Koo J, Koh S, Wu JY, et al. FDG-PET/MRI coregistration improves detection of cortical dysplasia in patients with epilepsy. Neurology. 2008;71(20):1594-601. https://doi.org/10.1212/01.wnl. $0000334752.41807 .2 f$

19. Rubí S, Setoain X, Donaire A, Bargalló N, Sanmartí F, Carreño M, et al. Validation of FDG-PET/MRI coregistration in nonlesional refractory childhood epilepsy. Epilepsia. 2011:52(12):2216-24. https://doi.org/10.1111/.1.1528-1167.2011.03295x.

20. Fernández S, Donaire A, Serès E, Setoain X, Bargalló N, Falcón C, et al. PET/MRl and PET/MRI/SISCOM coregistration in the presurgical evaluation of refractory focal epilepsy. Epilepsy Res. 2015;111:1-9. https//doi.org/10.1016/j.eplepsyres.2014.12.011.

21. Desarnaud S, Mellerio C, Semah F, Laurent A, Landre E, Devaux B, et al. Correction to: 18F-FDG PET in drug-resistant epilepsy due to focal cortical dysplasia type 2: additional value of electroclinical data and coregistration with MRI. Eur J Nucl Med Mol Imaging. 2018;45(8):1465. https://doi.org/10.1007/s00259-018-4022-3. 
22. Oldan JD, Shin HW, Khandani AH, Zamora C, Benefield T, Jewells V. Subsequent experience in hybrid PET-MRI for evaluation of refractory focal onset epilepsy. Seizure. 2018;61:128-34.

23. Ding Y-S, Chen B-B, Glielmi C, Friedman K, Devinsky O. A pilot study in epilepsy patients using simultaneous PET/MR. Am J Nucl Med Mol Imaging. 2014;4(5):459-70. http://www.ncbinlm.nih.gov/pubmed/25143864\%0A http://www.pubmedcentral.nih.gov/articlerender.fcgi?artid=PMC4138140.

24. Shin HW, Jewells V, Sheikh A, Zhang J, Zhu H, An H, et al. Initial experience in hybrid PET-MRI for evaluation of refractory focal onset epilepsy. Seizure. 2015;31:1-4. https://doi.org/10.1016/j.seizure.2015.06.010.

25. Karis JP; Expert Panel on Neurologic Imaging. Epilepsy. Am J Neuroradiol. 2008;29(6):1222-24.

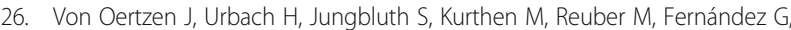
et al. Standard magnetic resonance imaging is inadequate for patients with refractory focal epilepsy. J Neurol Neurosurg Psychiatry. 2002;73(6):643-7. https://doi.org/10.1136/jnnp.73.6.643.

27. Saini J, Singh A, Kesavadas C, Thomas B, Rathore C, Bahuleyan B, et al. Role of threedimensional fluid-attenuated inversion recovery (3D FLAIR) and proton density magnetic resonance imaging for the detection and evaluation of lesion extent of focal cortical dysplasia in patients with refractory epilepsy. Acta Radiol. 2010;51(2): 218-25. https//doi.org/10.3109/02841850903433805.

28. Tschampa HJ, Urbach H, Malter M, Surges R, Greschus S, Gieseke J. Magnetic resonance imaging of focal cortical dysplasia: comparison of $3 D$ and $2 D$ fluid attenuated inversion recovery sequences at 3T. Epilepsy Res. 2015;116: 8-14. https://doi.org/10.1016/j.eplepsyres.2015.07.004.

29. Silva L, Amitai Y, Connors B. Intrinsic Oscillations of Neocortex Generated by Layer 5 Pyramidal Neurons. Science (80- ). 1991;251:432-5.

\section{Publisher's Note}

Springer Nature remains neutral with regard to jurisdictional claims in published maps and institutional affiliations.

Ready to submit your research? Choose BMC and benefit from:

- fast, convenient online submission

- thorough peer review by experienced researchers in your field

- rapid publication on acceptance

- support for research data, including large and complex data types

- gold Open Access which fosters wider collaboration and increased citations

- maximum visibility for your research: over $100 \mathrm{M}$ website views per year

At $\mathrm{BMC}$, research is always in progress.

Learn more biomedcentral.com/submissions 